FICÇÃo

\title{
o almanaque de johann peter hebel
}

Seleção E TRAduÇão de Samuel Titan JR.*

[*] Traduzi esta mini-antologia de Hebel e a conferência de Canetti em janeiro de 2005, durante uma estada em Berlim; agradeço a Joachim Bernauer e Heidi Wetz-Kubach, do Instituto Goethe, pela bela viagem $e$ ótima acolhida. Não teria sido possível reproduzir o texto de Canetti sem a simpatia e a prontidão de Friederike Barakat (Hanser), Isabel Piedrahita (Acer), Maria Amélia Mello (José Olympio) e Flávio Moura. Por fim, Heloisa Jahn, Ana Paula Pacheco, Márcio Suzuki e Roberto Schwarz fizeram a gentileza de comentar a primeira versão; a todos, muito obrigado.
Johann Peter Hebel teve uma curiosa fortuna em língua portuguesa ou, mais precisamente, junto aos leitores brasileiros. Escritor extraordinário, digno de figurar, ao lado de Goethe e Kleist, entre os grandes narradores alemães da virada do século XVIII para o XIX, Hebel merecera pouquíssimas traduções no Brasil: um conto no Mar de histórias de Paulo Rónai e Aurélio Buarque de Holanda, um outro vertido por este tradutor e estampado no suplemento Mais! da Folha de S. Paulo. Não é, entretanto, um nome obscuro, pelo menos não entre estudantes de letras, que o conhecem do ensaio de Walter Benjamin sobre "O narrador", publicado no Brasil na década de 1980. O foco do ensaio é o tipo do narrador tradicional radicado na oralidade, elo de transmissão de uma experiência coletiva que o antecede e transcende, contraposto ao narrador do romance, cuja matéria é a vivência individual sem sentido imediato para o protagonista ou para o leitor. Para traçar esse perfil, Benjamin não recorre à pesquisa etnográfica sobre a narrativa oral, preferindo estudá-lo tal como reaparece na obra de Nikolai Lieskóv, no âmbito russo, e de Hebel - o "incomparável Hebel” —, no domínio alemão.

$\mathrm{O}$ autor das onze histórias de almanaque (Kalendergeschichten) que se lerão a seguir nasceu na Basiléia, a 10 de maio de 1760, numa família simples de artesãos e camponeses. Perdeu o pai e a mãe ainda menino mas, graças a seus tutores, pôde seguir os estudos clássicos no ginásio luterano de Karlsruhe e na faculdade teológica de Erlangen. Uma vez ordenado, passou dez anos como professor de ginásios no sul de Baden, onde viveu pobremente em meio à paisagem esplendorosa dos Alpes e da Floresta Negra; dessa experiência, bem como do cultivo dos clássicos antigos e dos neoclássicos alemães, nasceria seu primeiro livro, uma antologia de Poemas alemânicos escritos em dialeto e publicados em 1803; um deles, Fugacidade (Vergänglichkeit), elogiado por ninguém menos que Goethe, tornou-se peça obrigatória nas antologias de poesia alemã. Em 1791, chamado a assumir um posto de professor de letras clássicas no ginásio de Karlsruhe, instalou-se definitivamente na 
cidade, onde fará uma notável carreira na igreja evangélica. Mas o episódio decisivo para nós, leitores, sobreveio em 1807, quando Hebel recebeu o encargo de renovar e redigir o almanaque oficial de Baden. Poeta de um livro só, já próximo dos cinqüenta anos, Hebel desempenhará a tarefa com entusiasmo até o ano de 1815, imprimindo ao almanaque um frescor narrativo que logo lhe garantiu enorme sucesso. Rebatizada como $O$ amigo da família renana (Der rheinländische Hausfreund), a publicação chegou a vender quarenta mil exemplares por ano, atraindo leitores além das fronteiras de Baden, bem como a atenção do grande editor Cotta, de Tübingen, que não tardou a encomendar uma antologia das melhores historietas. Publicado em 1811, o livro faria a fama de Hebel: trata-se do Florilégio ou Caixinha de tesouros do amigo da familia renana (Schatzkästlein des rheinischen Hausfreundes). Apesar ou, quem sabe, por causa do sucesso obtido, Hebel abandonou a redação do almanaque em 1815, após uma rusga com autoridades católicas de Baden, e só voltaria a assumi-lo em 1819, por um número apenas. Nessa mesma altura, sempre mais absorvido pelas obrigações pedagógicas e eclesiásticas, Hebel deu início em 1818 a uma nova empresa narrativa: uma versão para jovens alunos das Histórias bíblicas (Biblische Geschichten), publicadas em 1824, dois anos antes da morte do autor, que faleceu em 22 de setembro de 1826, na cidadezinha de Schwetzingen, em meio a uma viagem de inspeção escolar.

As histórias estampadas a seguir dão uma pequena mostra da força e da diversidade da criação de Hebel. Certamente, a chave para sua obra madura, como Benjamin percebeu, está na criação de uma voz central, de um narrador, aquele "amigo das famílias" ou Hausfreund que, no frontispício do almanaque original, sentava-se entre camponeses e contava-lhes episódios e anedotas da terra e do estrangeiro. Mas nem por isso se espere dele um tom único, popularesco ou folclórico, longe disso. O narrador hebeliano mistura, em doses justas, a oralidade do relato à armação da sintaxe; sua linguagem, de fluência coloquial, faz eco também à Bíblia alemã de Lutero; às vezes, sua matéria provém da tradição imemorial, mas há ocasiões em que se faz de reporter para relatar passagens das guerras napoleônicas; sabe contar histórias de proveito sem dispensar o paradoxo; tem intenção edificante, mas sua religião é feita menos de dogmas do que de uma moralidade esclarecida, coisa de quem não passou em vão pelo século do Iluminismo. Encarnada no narrador, essa síntese, que é tanto literária como histórica, garantiu a permanência e, mais que isso, a atualidade de Hebel. De fato, são inúmeros os prosadores e pensadores de língua alemã que, desde o começo do século XX, deixaram-se tocar e inspirar pelas brevíssimas histórias de almanaque do modesto mocinho de Basiléia: vale lembrar, entre outros, os nomes de Robert Walser, Bertolt Brecht, Franz Kafka (releia-se o conto "A próxima aldeia" à luz de "Pouso breve"!), Elias Canetti (que lhe presta homenagem em $A$ língua absolvida e na conferência reproduzida mais abaixo), Ernst Bloch, 
[1] Pronunciado à alemã, o nome da cidade holandesa soa como "dores", "sofrimentos" ou "penas". [N. T]
Martin Heidegger, Peter Bichsel e, há pouco, Durs Grünbein, que dedica as primeiríssimas páginas de O primeiro ano (2001) ao "Reencontro Inesperado" de 1811.

Mas basta, paremos por aqui, e vejamos o que Hebel tem a dizer ao leitor brasileiro de 2005 .

\section{DESGRAÇA NA CIDADE DE LEIDEN}

Essa cidade chama-se Leiden há tempos imemoriais e nunca soube o porquê até 12 de janeiro do ano de 1807. ${ }^{1}$ Fica à margem do Reno, já na Holanda, e antes desse dia contava onze mil casas, habitadas por quarenta mil pessoas, e era, depois de Amsterdam, a maior cidade do reino. Naquela manhã, todos acordaram como todo dia; este fazia suas preces, aquele deixava por menos, e ninguém pensava em como andariam as coisas à noite, muito embora um navio com setenta barricas de pólvora estivesse atracado na cidade. Todos almoçaram com gosto, como todo dia, muito embora o navio ainda estivesse lá. Mas à tarde, quando o relógio da torre maior indicava as quatro e meia - a gente industriosa dava duro em casa, as mães dedicadas embalavam seus filhinhos, os mercadores tratavam de seus negócios, as crianças estudavam na escola, os ociosos se entediavam entre as cartas e as canecas na taberna, o mais prudente cuidava do dia de amanhã, do que comeria, beberia ou vestiria, algum ladrão metia uma chave falsa em porta alheia -, à tarde, de repente, ouviu-se um estouro. O navio com as setenta barricas de pólvora pegou fogo, saltou pelos ares, e num instante (rápido assim como se lê), num instante ruas inteiras cheias de casas mais tudo o que por ali morava e vivia foi destruído e reduzido a pilhas de pedras ou terrivelmente danificado. Centenas de pessoas foram enterradas, vivas ou mortas, sob os escombros ou feridas gravemente. Três escolas foram ao chão com todas as crianças; homens e animais que se encontravam nas ruas próximas ao desastre foram lançados para o alto pela força da pólvora e caíram ao chão em estado lastimável. Por desgraça, irrompeu um incêndio que rápido grassou por toda parte e que não houve meio de apagar, pois muitos armazéns repletos de óleo e gordura de peixe foram atingidos. Oitocentas casas entre as mais bonitas desmoronaram ou tiveram de ser demolidas. Viu-se então como as coisas podem mudar de feição da manhã para a noite, e não só para um pobre homem, mas também para uma cidade grande e populosa. O rei da Holanda logo determinou um prêmio considerável para cada homem resgatado com vida. Também os mortos retirados dos escombros foram levados à prefeitura, de modo que os familiares pudessem lhes dar enterro digno. Grande foi o esforço para socorrer a todos. Apesar da guerra entre a Inglaterra e a Holanda, vieram de Londres vários navios cheios de provisões e dinheiro para os desgraçados, e isso é de se louvar - pois a guerra não deve jamais penetrar o coração dos homens. Já basta o mal que faz quando troveja diante das portas e dos portos. 


\section{O SONHADOR PRECAVIDO}

Quanta gente simplória vai por este mundo!

Um forasteiro certa vez passou a noite na cidadezinha de Witlisbach, no cantão de Berna, e, quando quis dormir e já se despira até a camisa, tirou da trouxa um par de pantufas, calçou-as, amarrouas aos pés com ligas e deitou-se assim na cama. Então um outro viajante hospedado no mesmo quarto perguntou: "Meu amigo, por que faz isso?". Ao que o primeiro replicou: "Por precaução, pois uma vez sonhei que pisava num caco de vidro. Mesmo dormindo, senti tanta dor que por nada no mundo voltaria a dormir descalço de novo".

\section{POUSO BREVE}

O chefe da posta disse a um judeu que chegara à estação com dois cavalos: "Daqui para a frente são precisos três cavalos. A estrada segue ladeira acima e o leito está cheio de valas. São três horas até o final". O judeu perguntou: "E quanto tempo levo com quatro cavalos?". "Duas horas." "E com seis?" "Uma hora." "Sabe de uma coisa?", disse por fim o judeu. "Atrele oito, assim não preciso nem partir!"

\section{SUVóRoV}

Todo homem deve ser capaz de exercer domínio sobre si mesmo, de outro modo não será um homem bravo e respeitável - e quem assentou algo por justo de uma vez por todas deve agir conformemente não uma vez por todas, mas sempre. O general russo Suvórov, bem conhecido de turcos e polacos, italianos e suiços, era homem de ordens ríspidas e rígidas. Mas o mais nobre é que se submetia às próprias ordens, como se fosse um sujeito qualquer, e não Suvórov, e muitas vezes seus ajudantes deviam lhe ordenar isso ou aquilo em seu próprio nome, ao que atendia escrupulosamente. Certa ocasião, ficou furioso por conta de um soldado que descuidara de alguma coisa em serviço e começou a espancá-lo. Então um dos ajudantes tomou coragem, pensou que afinal de contas só queria prestar um serviço ao soldado e ao general, adiantou-se e disse: "O general Suvórov ordenou que ninguém se deixe arrebatar pela cólera!". Suvórov deteve-se no ato e disse: "Se o general ordenou, só resta obedecer".

\section{O JUIZ ASTUTO}

É bem sabido que nem tudo vai tão mal no Oriente. Dizem que justamente por lá deu-se o episódio que segue. Um homem rico 
perdera por descuido uma considerável soma de dinheiro costurada num pano. Anunciou a perda e, como é de costume, ofereceu ao bom sujeito que o encontrasse uma recompensa - e de cem táleres. Logo apareceu um homem direito e honrado. "Encontrei o dinheiro! Deve ser este aqui! Tome o que é seu!” Disse isso com o olhar desanuviado de um homem honesto e de uma consciência em paz, o que era bonito de ver. O outro também se alegrou, mas só porque reencontrara o tesouro perdido - logo se verá a quantas andava sua honra. Contou o dinheiro enquanto pensava depressa em como negar a recompensa prometida. "Meu bom amigo," começou, "havia oitocentos táleres costurados no pano. Mas só restam setecentos. Imagino que tenha aberto uma das costuras e retirado os cem táleres da recompensa. E fez muito bem. Muito obrigado!" Isso não foi nada bonito. Mas a coisa não ficou por aí. A mentira tem pernas curtas, e quem com ferro fere, com ferro será ferido. O bom sujeito, que se importava menos com os cem táleres que com a reputação imaculada, assegurou que trouxera a trouxa assim como a encontrara e que a encontrara assim como a trouxera. No fim, foram ter com o juiz. Ambos confirmaram suas histórias: um, que havia oitocentos táleres costurados dentro do pano; o outro, que não tirara nada do achado e não tocara na trouxinha. Era um mato sem cachorro. Mas o juiz astuto, que parecia conhecer de antemão a honradez de um e as más intenções do outro, resolveu o caso da seguinte maneira. Ordenou que ambos confirmassem tudo firme e solenemente tudo o que haviam dito e sentenciou: "Assim sendo, se um perdeu oitocentos táleres e o outro encontrou apenas setecentos, então o dinheiro deste último não pode ser aquele a que o primeiro tem direito. Você, honrado amigo, fique com o dinheiro que encontrou e conserve-o até que apareça quem tiver perdido apenas setecentos táleres. E a você, não sei qual conselho dar, exceto que tenha paciência até que se apresente alguém com os oitocentos táleres". Assim falou o juiz, e assim a coisa ficou.

\section{COMO SE FAZ A BARBA POR CARIDADE}

Um pobre homem de barba cheia e negra entra numa barbearia e, em vez de um pedaço de pão, pede ao patrão que tenha a bondade de lhe fazer a barba, para que volte a ter cara de bom cristão. O barbeiro empunha a pior navalha, pensando: "Vou lá estragar o fio de uma navalha boa por nadica de nada?". Enquanto raspa e retalha o pobrediabo, que não pode dizer nada, pois o barbeiro trabalha de graça, um cachorro começa a uivar no pátio. O patrão pergunta: "Mas o que tem o Lobo que tanto gane e uiva?". Um fulano diz: "Não sei, não". Um outro diz: "Nem eu". Mas o pobre-diabo debaixo da navalha responde: "Vai ver que também estão barbeando o bicho por amor a Deus". 
$\mathrm{Na}$ guerra dos anos noventa, quando a margem de lá do Reno estava tomada por sentinelas franceses e a de cá por suábios, um francês desocupado gritou para um sentinela alemão: "Filou! Filou!". Isso quer dizer, em bom alemão, "patife". Mas o honesto suábio nem suspeitou da malícia, pensou que o francês perguntava: "Wieviel Uhr?", ${ }^{2}$ e de bom-grado respondeu: "Três e meia!".

\section{MOSES MENDELSOHN}

Moses Mendelsohn era de religião judaica e contador de um comerciante que, ao que dizem, não inventou a pólvora. Era também muito sábio e devoto, e por isso contava com a estima e o apreço dos homens mais respeitáveis e eruditos. E é muito certo que seja assim, pois não se deve julgar mal a cabeça pela barba que nela cresce. Esse Moses Mendelsohn deu, entre outros, o seguinte exemplo de satisfação com o próprio destino. Certo dia, um amigo foi visitá-lo, deu com ele suando em cima de uma conta difícil, e disse: "É uma pena, meu bom Moses, e é inaceitável que uma cabeça tão inteligente como a sua tenha que ganhar o pão servindo a um homem que não merece lhe servir um copo d'água. O seu mindinho não é mais sabido do que ele inteiro, com todo aquele corpanzil?". Um outro teria ruminado essas palavras, teria jogado a pena e o tinteiro pelos ares e pedido as contas ao patrão no mesmo instante. Mas o sensato Mendelsohn deixou o tinteiro em paz, meteu a pena atrás da orelha, voltou-se tranqüilo para o amigo e disse o seguinte: "Tudo está certo assim como está, como a Providência sabiamente quis. Pois desse modo meu patrão tira bom proveito dos meus serviços e eu tenho do que viver. Mas, fosse eu o patrão e ele, o contador, eu não saberia o que fazer dele".

\section{CAVALgada InSÓLIta}

Um homem cavalga seu burrico no rumo de casa e deixa que o filho caminhe ao lado. Vem um passante e diz: "Isso não está certo: o senhor cavalgar e fazer o filho andar; o senhor tem membros mais fortes". Então o pai desmontou do burrico e deixou o filho cavalgar. Vem de novo um passante e diz: "Não está certo, menino, você cavalgar e fazer o pai andar; você tem pernas mais jovens". Então os dois montaram e cavalgaram um tanto mais. Vem um terceiro passante e diz: "Mas que desatino: dois sujeitos em cima de um pobre animal! É de pegar uma vara e derrubar os dois!". Então os dois desmontaram, e seguiram os três a pé, à esquerda o pai, à direita o filho, no meio o burrico. Vem um quarto passante e diz: "Mas que trio curioso. Já não basta dois terem
[2] "Que horas são?", sempre em bom alemão. [N.T] 
de andar? Não seria mais fácil se um cavalgasse?". Então o pai amarrou as patas da frente e o filho amarrou as patas de trás, passaram entre elas um galho forte que estava à margem do caminho e carregaram o burrico em cima dos ombros.

Assim acaba quem dá ouvidos ao primeiro que vier.

REENCONTRO INESPERADO

Em Falun, na Suécia, há bons cinqüenta anos ou mais, um jovem mineiro despediu-se com um beijo da noiva jovem e bela e lhe disse: "No dia de Santa Lúcia nosso amor será abençoado pela mão do pastor. Então seremos marido e mulher, e vamos construir nosso próprio ninho". "Onde a paz e o amor vão sempre morar", respondeu a bela noiva, com um sorriso gentil, "pois vocêé tudo para mim, e sem vocêeu prefiro o túmulo a qualquer outro lugar." Mas quando, pouco antes do dia de Santa Lúcia, ela pediu ao pastor que conclamasse pela segunda vez à igreja "quem soubesse de obstáculo que impedisse estas pessoas de se unirem em matrimônio", foi a morte que se apresentou. Pois no dia seguinte, ao passar pela casa da noiva em seus trajes negros de mineiro - o mineiro veste sempre o seu sudário - o jovem bateu duas vezes à janela e ainda lhe desejou "Bom dia!"- mas "Boa noite!", nunca mais. Nunca mais voltou da mina, e foi em vão que, naquela mesma manhã, ela bordou para ele, para o dia do casamento, um lenço negro de barra vermelha; como ele não voltasse, ela abandonou o lenço, chorou por ele e jamais o esqueceu. Nesse meio-tempo, a cidade de Lisboa, em Portugal, foi destruída por um terremoto e a Guerra dos Sete Anos chegou ao fim e o imperador Francisco I morreu e os jesuítas foram suspensos e a Polônia, dividida e a imperatriz Maria Teresa morreu e Struensee foi executado, a América se libertou e as forças combinadas da França e da Espanha não puderam conquistar Gibraltar. Os turcos encurralaram o general Stein na Cova dos Veteranos, na Hungria e o imperador José morreu também. O rei Gustavo da Suécia conquistou a Finlândia aos russos e a Revolução Francesa e a grande guerra irromperam e o imperador Leopoldo II desceu também ao túmulo. Napoleão conquistou a Prússia e os ingleses bombardearam Copenhague e os lavradores semeavam e ceifavam. O moleiro moía, os ferreiros martelavam e os mineiros cavavam atrás dos veios de metal em sua oficina subterrânea. Mas no ano de 1809 , pouco antes ou depois do dia de São João, quando tentavam praticar uma passagem entre dois poços a bons trezentos côvados sob a terra, os mineiros de Falun retiraram do entulho e do vitríolo o cadáver de um rapaz, todo embebido em sulfato ferroso, de resto intacto e inalterado, a tal ponto que era perfeitamente possível reconhecer suas feições e sua idade, como se ele tivesse morrido uma hora antes ou cochilado durante o trabalho. Mas quando o trouxeram para o ar livre, pai e mãe, amigos e 
conhecidos, todos tinham morrido havia muito, ninguém conhecia o rapaz adormecido ou sabia de sua desgraça, até que chegou a antiga amada do mineiro que um dia descera para o seu turno e nunca mais voltara. Envelhecida e encarquilhada, chegou apoiada numa muleta $e$ reconheceu o noivo; mais radiante que sofredora, deixou-se cair ao lado do querido cadáver e, depois de se refazer do abalo na alma, disse por fim: "É o noivo por quem chorei durante cinqüenta anos e que Deus me permite ver de novo antes do meu fim. Oito dias antes do casamento, ele desceu à mina e nunca mais voltou". Então o ânimo de todos à volta foi tomado de tristeza e lágrimas, ao ver como a noiva de outrora tinha as feições murchas e sem viço da velhice e o noivo conservava sua beleza juvenil; e como, depois de cinqüenta anos, tornava a despertar nela a chama do amor juvenil, sem que ele abrisse a boca para sorrir ou os olhos para reconhecê-la; e como finalmente ela, a única a conhecê-lo e a ter direitos sobre ele, finalmente pediu aos mineiros que o levassem até a sua casinha, enquanto preparavam o túmulo no cemitério. No dia seguinte, quando o túmulo ficou pronto no cemitério e os mineiros vieram buscar o moço, ela abriu uma caixinha, tirou para ele o lenço de seda negra e barra vermelha e o acompanhou em seus trajes domingueiros, como se fosse dia de casamento e não de enterro. E no cemitério, quando o deitaram no túmulo, ela disse: "Durma em paz, mais um dia ou dez, no frio leito de núpcias, e não se aborreça. Tenho pouco a fazer, venho logo, e logo será um novo dia". "O que a terra devolveu, ela não tira outra vez", disse ainda, afastando-se, e olhou uma vez mais para trás.

\section{KANNITVERSTAN}

Não passa dia sem que o homem tenha ocasião, ao menos se quiser, seja em Emmendingen ou Gundelfingen, seja ainda em Amsterdam, de refletir sobre a inconstância de todas as coisas terrenas e de se dar por satisfeito com seu próprio destino, por mais que o mar não esteja para peixe. Mas foi por via bem mais torta que, em Amsterdam, um jovem aprendiz alemão escapou do erro e reconheceu a verdade. Pois tão-logo chegou a essa cidade grande e rica, repleta de casas suntuosas, navios balouçantes e homens atarefados, deu com os olhos numa casa grande e bonita como não vira outra em todo o caminho de Tuttlingen a Amsterdam. Admirou longamente a construção apurada, as seis chaminés no telhado, as belas cornijas e as janelas altas, mais altas que a porta da casa paterna. Finalmente, não pôde se impedir de chamar um passante. "Meu bom amigo", interpelou-o, "o senhor não saberia me dizer a quem pertence essa casa maravilhosa, com essas janelas cheias de tulipas, sécias e goivos?" Mas o sujeito, que presumivelmente tinha mais o que fazer e infelizmente sabia tanto alemão quanto o outro sabia holandês, ou seja, nada, 
respondeu curto e grosso: “Kannitverstan!", e safou-se dali. É uma palavra holandesa ou, pensando bem, são três, que significam em alemão simplesmente "Não o entendo!". Mas o bom estrangeiro pensou que aquele fosse o nome da pessoa por quem perguntara. "Deve ser podre de rico, esse senhor Kannitverstan”, pensou ele e seguiu em frente. De tanto andar de cá para lá, chegou afinal ao golfo que ali chamam de "Het Ei” ou, em alemão, "o Ypsilon". Eram navios e mais navios, mastros e mais mastros; e, de início, ele não soube como daria conta de ver e contemplar todas aquelas coisas notáveis, até que um navio dos grandes chamou sua atenção: chegara havia pouco das Índias Orientais, e o estavam descarregando naquele instante. Em terra, já se viam pilhas e fileiras de fardos e caixotes. Outros mais eram rolados para fora, além de tonéis de açúcar e café, arroz e pimenta, salpicados, com o perdão da palavra, de titica de rato. Depois de espiar por um bom tempo, acabou por perguntar a um sujeito que vinha carregando um caixote em cima do ombro como se chamava o felizardo para quem o mar trazia todas aquelas mercadorias. "Kannitverstan!", foi a resposta. Então ele pensou: "Ah, vejam só! Não é de admirar, um sujeito que recebe tantas riquezas do mar pode muito bem construir uma casa daquelas, com tantas tulipas em vasos dourados na janela!". Foi voltando sobre seus passos, pensando tristonho em como era um pobre coitado entre tanta gente tão rica neste mundo. Mas, justamente quando pensava: "Se pelo menos uma vez na vida eu me desse tão bem quanto esse senhor Kannitverstan...", chegou a uma esquina e deu com um longo féretro. Quatro cavalos embuçados de negro puxavam um carro fúnebre coberto igualmente em pano negro; iam lentos e graves, como se soubessem que levavam um morto para o descanso final. Uma fila comprida de amigos e conhecidos do falecido vinha atrás, aos pares, enfronhados em mantos negros, e calados. Um dobre de sinos ressoava ao longe. Nosso estrangeiro foi tomado de um sentimento de tristeza a que nenhum bom homem escapa quando vê passar um féretro, e ficou ali parado, contrito, chapéu nas mãos, até que o cortejo passasse. No fim, avançou até o último da fila, que calculava em silêncio quanto ganharia com seu algodão se o quintal subisse mais dez florins, puxou-o de leve pelo manto e, pedindo-lhe sinceras desculpas pelo incômodo, disse: "Deve ter sido um bom amigo do senhor, esse por quem os sinos dobram, para o senhor ir assim tão aflito e pensativo". "Kannitverstan!", foi a resposta. Então, duas grossas lágrimas vieram aos olhos do nosso bom camarada de Tuttlingen, e seu coração se apertou e aliviou ao mesmo tempo. "Pobre Kannitverstan", exclamou, "o que lhe restou de tanta riqueza? O mesmo que a minha pobreza me dá: um sudário e um lençol - e, de todas aquelas flores, talvez um alecrim sobre o peito frio, quem sabe uma arruda." Com tais pensamentos acompanhou o cortejo até o túmulo, como se fosse coisa sua, viu o suposto sr. Kannitverstan descer ao jazigo e, sem entender uma única palavra, comoveu-se mais com a prédica em holandês do 
que com muita em alemão a que não dava ouvidos. Por fim, de coração mais leve, foi-se embora com os demais, devorou com apetite um naco de queijo de Limburg numa estalagem em que se falava alemão e, dali em diante, quando queria se acabrunhar porque tanta gente era tão rica e ele, tão pobre, só precisava pensar no sr. Kannitverstan, de Amsterdam, que tinha a casa tão bela, o navio tão rico, a cova tão justa.

Leia sobre Johann Peter Hebel no texto introdutório a esta coletânea. 


\section{EMBRANCO}

\section{3}


ENSAIO

244 